Pre-press version of:

Duxbury, N., S. Silva, and T. Vinagre de Castro. (Forthcoming). Creative tourism development in small cities and rural areas in Portugal: Insights from start-up activities. In D. A. Jelinčić and Y. Mansfeld (Eds.), Creating and Managing Experiences in Cultural Tourism. World Scientific Publishing.

\title{
Creative tourism development in small cities and rural areas in Portugal:
}

\section{Insights from start-up activities}

Nancy Duxbury, Silvia Silva, and Tiago Vinagre de Castro

The rise of the 'experience economy' (Pine and Gilmore, 1998) has led to the recognition of experiences as intrinsically embodying economic (and other) value. In the tourism context, this translated into a focus on creating memorable and unique events and activities, initially designed as 'staged experiences'. However, in a 'prosumer' culture with a growing desire for interaction and involvement, this progressed further, with tourists increasingly desiring 'co-creation' experiences and taking on more active roles (Campos et al., 2015). In parallel, tourists' growing desire for direct and meaningful involvement in the face of 'massified' cultural tourism offers and organized experiences has fuelled the development of 'creative tourism' (Richards and Wilson, 2007). In this context, creators of creative tourism experiences need to think carefully about the aspects of creativity that are related to its place and that offer creative tourists a specific motivation to visit (Richards, 2011).

This chapter begins by outlining some of the key lines of discussion in the field of creative tourism and then provides an overview of CREATOUR, a national creative tourism research-and-application project in Portugal, and its project pilots, presenting a few examples to illustrate the types of creative activities designed and how they connect to the place in which they are being developed and implemented. Then, 
reflecting on discussions with pilot organizations during the 'start-up' phase of the project, a series of challenges and issues that have been encountered are discussed. In closing, lessons learned in the start-up stages about the importance of embedding place-specificity in the development of creative tourism offers in smaller cities/towns and rural areas are reinforced.

\section{Creative tourism}

In 2000, Richards and Raymond presented what is considered to be the first definition of creative tourism, describing it as: "Tourism that offers visitors the opportunity to develop their creative potential through active participation in learning courses and experiences that are characteristics of the holiday destination where they are passed" (p. 18). While other definitions have followed (see, for example, UNESCO, 2006; Raymond, 2007; Jelinčić and Žuvela, 2012; Blapp, 2015), this initial definition continues to serve as a touchstone in the field. A growing interest in intangible elements of culture coupled with discontent with the massification of traditional cultural tourism has generated a demand among tourists for travel and destinations that allow them to enjoy an authentic experience, and to explore new forms of interaction and socialization with the people and places they visit. The profile of tourists has evolved as increasingly aware, informed, and demanding.

Tourists visit places for their creative environment and the opportunity to experience creative activities (Triarchi and Karamanis, 2017), with several authors addressing relations between the practice of traveling and creativity in recent years. For example, Bloom et al. (2014) establish that recreational travel offers an excellent opportunity to diversify experiences, and many researchers have examined how divergent and 
multicultural experiences are associated with creativity (e.g., Leung et al., 2008; Maddux et al., 2010). Building from this, today we are observing a societal trend towards greater demand for creative tourism activities going beyond the 'do it yourself' movement and incorporating creative activity and self-expression as key to personal well-being. This zeitgeist links to the 'meaningful' and 'mindful' travel niche as well as the growing desire to disconnect and temporarily 'unplug' from the urban frenzy and professional demands of everyday life and to 'get one's hands dirty' again.

However, creative tourism implies not only that tourists need to be creatively involved, but that the destination itself also needs to become more creative in designing 'characteristic' experiences. The evolutionary relationship between creativity and tourism forces us to rethink important aspects of contemporary tourism. First, tourists not only visit places, they also make them, and the goal of creative tourism should be to ensure that co-production occurs through an exchange of skills and knowledge with those who are visited (Richards, 2011). Second, the progressive appreciation of intangible elements such as identity, lifestyle, traditions, etc. (OECD, 2009; Richards and Wilson, 2007) focuses attention on the identity traits and the respective valuations of assets for tourism purposes. Following from both of these factors, we contend that the complementary relationship between space and identity should be a keystone for the emergence of creative tourism in rural areas and small towns, with particular attention to the symbolic dimensions of local culture that people have developed in their relationship with that space. 
As the 2014 OECD report on Tourism and the Creative Economy points out, the added value potential of creative activities can be enhanced by measures designed to "support content development, link creativity to place, build knowledge and capacity, and strengthen network and cluster formation" (p. 8). Linking creative activity to place in a context of tourists seeking 'authentic' cultural tourism experiences foregrounds the development of workshops and related participatory creative activities that are based on and informed by local history, traditions, and cultural expressions - and that are also envisioned, designed, and embedded locally. In this sense, tourism is seen, in its broadest sense, as a reciprocal exchange that, for the territory and its residents, can translate into an opportunity for identity recognition, awareness of its heritage and cultural richness, quality improvement of life, improvement of attractiveness, and territorial image (Juanchich, 2007).

\section{The CREATOUR project in the Portuguese tourism context}

Tourism is currently one of the main drivers of the Portuguese economy and, in the past few years, tourism activity has been growing exponentially. In 2017, Portugal was one of the 20 largest travel destinations in the world, surpassing 12 million tourists (UNWTO, 2016). In this growing context of tourism activity in Portugal, concerns have arisen regarding the negative impacts of tourism activity associated with the massification and standardization of supply and destinations, particularly in the big cities of Lisbon and Porto and in the most touristic regions, Algarve and Madeira. Consequently, and in line with the trends of diversification of the sector worldwide, creative tourism initiatives are emerging in Portugal. 
CREATOUR: Creative Tourism Destination Development in Small Cities and Rural Areas is a national, three-year, research-and-application project (2016-19) to develop and pilot an integrated approach for creative tourism in small cities and rural areas in Portugal. It combines multidisciplinary research with the development of a network of 40 creative tourism pilots, 20 selected in 2017 and 20 selected in 2018 . The vision of creative tourism guiding CREATOUR's pilot activities is centred on active creative activity encouraging personal self-expression and interaction between visitors and local residents, inspired by local endogenous resources (place and people), and designed and implemented by local residents. A working definition of creative tourism has been established as sustainable small-scale tourism that provides a genuine visitor experience by combining an immersion in local culture with a learning and creative process.

In the context of 'over-tourism' in many large cities and coastal resort communities, CREATOUR aims to develop attractive offers in 'other', less visited areas, focusing on rural areas and small towns and cities. CREATOUR promotes small-scale, interactive creative tourism activities, building from local cultural traditions, skills, knowledge, and emerging artistic practices. The initiatives are supported by a network offering not only visibility through critical mass, but also aimed to support research, co-learning, and capacity building. The project aims to contribute to the sustainable development of local communities across Portugal, and encourages (and will monitor) the wider community impacts of the creative tourism pilots.

CREATOUR's pilot projects were selected through two national open calls (with deadlines in January and November of 2017), with five organizations selected during 
each call in each region: Norte, Centro, Alentejo, and Algarve. Applications were reviewed according to an array of criteria: i) cultural value of the activities proposed; ii) the creative nature of the activities proposed; iii) capacity of tourism attractiveness; iv) impact of the project in terms of community development; v) diversity of focus of the proposals; and vi) capacity and commitment to work with the research team during the project. The pilots play an important role in the project through the development and implementation of a set of creative tourism activities and are viewed as co-researchers in CREATOUR.

To support the initial project planning stages and get to know the selected pilots better, a series of interactive regional IdeaLabs was designed and implemented in April and May 2017. The CREATOUR IdeaLabs are unique and innovative events that are both a research tool and moment for guidance and sharing among researchers and pilots, supporting knowledge exchange and co-creation. Then, at a quick pace, the pilots continued to develop their creative tourism activities, presenting their plans at a National IdeaLab in May, with initial workshops offered beginning in June 2017.

\section{Creative tourism start-ups: Connecting creativity to place}

During the initial year of the CREATOUR project, the research team began monitoring the start-up of the first 20 creative tourism pilot initiatives located in rural areas and small cities throughout Portugal. For most of the pilots, creative tourism activities were a new type of activity, so the first year primarily focused on the design and development of workshops and related activities, with initial offers serving as both tourism product and a 'prototype test' of these ideas. In this section, we describe some of the characteristics of these creative tourism start-ups, pointing out how the 
initiatives foreground place-specificity. The empirical data for this article is based on conversations/focus groups with the pilot organizations held in the spring and fall of 2017, complemented with observations from researcher site visits to some of the pilots during the summer and fall of 2017.

As outlined above, the pilots were selected from open calls in which all types of organizations could apply. Among the initial 20 pilots, different types of organizations were selected, including not-for-profit art and cultural associations, small entrepreneurial businesses, municipalities, regional development associations, and a few inter-organizational partnerships developed for the call. Of note, among these pilots, leading roles were taken up by the municipalities, regional development associations, and a few private entrepreneurs to launch and coordinate local networks of creative tourism offers in collaboration with a range of independent operators. Other organizational models included the integration of creative activities as the defining feature of small-scale festivals; and tradition-based businesses that include creative tourism and other types of activities, with attention to both business development as well as the wider socio-cultural and economic development of the community in which they are based.

From June 2017, creative tourism activities began appearing in all Portugal regions, operating in multiple locations, based on local traditions and artistic expression, and in relation with nature and place. From a cultural/content perspective, some examples are:

- craft workshops - textile, pottery, ceramics, leather, metal, wood, etc.; 
- fine arts workshops - painting, sculpture, drawing, and illustration;

- photography, video, and digital arts workshops;

- performing arts workshops and community-engaged, participatory artistic residencies;

- $\quad$ storytelling sessions and workshops;

- gastronomy-focused workshops;

- creative and interpretative 'Walks \& Visits' involving creation activities;

- ancestral traditions workshops and active participation activities; and

- raw materials production and work cycles - of salt, linen, wool, clay, marble, wicker, etc.

In some cases, the creative tourism offers were scheduled within larger events and attractions, while in other cases they were offered as stand-alone workshops on weekends (as often seen in urban models). The pragmatic realization of the time and distances involved in travelling to participate in these activities - some are truly remote from 'big cities' — as well as the travelling 'circuits' and habits within Portugal, required attentive consideration to the relationship between the size or scope of the creative tourism offer, the efforts required to get there, and its attraction capacity.

Overall, CREATOUR places a strong emphasis on place, which operationalizes on a number of levels: local residents lead the design and development of the pilot activities, local community involvement in the activities is strongly encouraged, and significant and 'special' natural and historic places provide some contextualizing sites for the activities. All pilot projects developed and offered creative tourism activities 
that embody local traditions or expertise, local history, and ways of life blended with other specifics of the cultural and local landscape of the locations where activities were organized, whether in a small city or a rural area. This place-sensitive development process served to connect creativity to place and create genuine, immersive, and creative experiences. For example:

- Luzlinar, a cultural organization based in the village of Feital, uses the Serra Estrela landscape as inspiration and setting for contemporary art workshops (based on, for example, photography, video, sketching/painting, and musiccreation) and develops creative tourism workshops to lead the preservation and revitalization of shepherds' shelters and routes in the region (in which visitors participate). In this sense, Luzlinar promotes culture-based, creative activities that will bring visitors to the local villages and also preserve and disseminate local heritage.

- Mosaico - Conímbriga and Sicó is a Roman heritage project developed in archaeological sites that feature Roman ruins with mosaic floors still intact. By participating in Mosaico's workshops, people get to know the sites' Roman legacies, learn about the mosaic artwork and its motifs, and create their own mosaic, relating this ancient art form to contemporary ones through 'reinvention' approaches.

- In the municipality of Reguengos de Monsaraz, the traditional Casa do Barro (Clay House) provides visitors an opportunity to encounter the traditional pottery craft specific to this locale. Visitors meet local craftsmen, learn from them about the clay processing cycle and the importance and role of this activity in the local and regional ways of life, and are provided an opportunity 
to design their own 'Alentejo-inspired' plates to take home. While they are there, visitors also make contact with local food preparation traditions relating to this craft (and participate in tastings!).

- In the North of Portugal, the small enterprise VERde NOVO focuses on the cycle of linen, as one of the ancient traditional activities in two small villages, Cerva and Limões, which are set in a very peculiar and unique rural landscape that also serves as inspiration. Visitors are guided to participate actively in several steps related to the linen cycle, from sowing, harvesting, and dying, to weaving. The workshops and other activities involve local weavers who work in the communities using traditional techniques.

Through such creative experiences, visitors are provided close-up and interactive opportunities to get to know the destination and its community in terms of its history, culture, traditions, people, and stories and then to use this knowledge as raw material or inspiration for processes of creation and self-expression.

\section{Key issues}

In the early start-up phase, a number of key issues emerged prominently in discussions with the pilot organizations, which will be addressed as the project proceeds:

Communication and promotion - A top concern among most pilots was how to attract visitor-participants, an issue rooted in effectively defining, reaching, and attracting the envisioned participant-tourists. Pilots tended to promote the activities via their usual communication channels, including printed flyers and posters and social media, and 
some obtained local newspaper coverage of their initiatives. However, the time period during which the activities were announced was often quite short, an issue that pilots recognized. Overall, it appeared that in this early stage, efforts were more focused on designing and sorting out the operational requirements of implementation than conducting market research to discover and contact niche groups and organizations (nationally and internationally) that could be interested in the offer. The creation and launch of the new activities naturally took precedence over these more long-term development activities at the time. Also, during the first summer season, while a CREATOUR Facebook page was available as a central channel for announcements, the full project website was not yet completed (a temporary website was in place but it did not have the full capacities of the final website), which also limited project-wide promotions.

Risk of a production-led (or supply-led) model, with activities primarily based on local resources and pilots' interests and skills - The CREATOUR project embodies an open approach to locally important ideas, inspirations, and collaborative explorations. We contend that this is an appropriate guiding strategy in the context of a creative experiment and the desire to foster new and different, to diversify current offers, to surprise, and to be flexible and innovative in development trajectories. In this context, encouraging grassroots-led experimentation and new ideas is the project's initial priority, with importance of 'market' secondary once the initial ideas and offers are defined. However, this creative ideas-based approach also brings a risk (cf. Raymond, 2007) concerning the degree of 'take up' of the offers, and also the speed at which this could happen: on one end, there is the nagging question, 'Will anyone be interested in what we want to offer?' and, on the other end, pragmatic 
questions about the operational capacity of each pilot and the carrying capacity of the small communities in which they are embedded.

Creative tourism is a side activity for the pilot organizations, especially in these beginning stages - This situation means that the proponents of the pilot activities do not have 'ideal conditions' in which to focus on these initiatives fully. Pragmatically, this means that the amount of time and efforts they are able to dedicate to background research, development, and planning efforts is limited. This is an overarching condition that constrains the rate of development of the pilots as well as a factor to be considered in designing collaborative research activities.

Making activities economically sustainable - For most pilots, designing and offering creative tourism workshops and related activities is a new enterprise. Given the nature of the learning-by-experimenting nature of the project, the implementation of the offers is conducted in a manner in which feasible business models, perhaps mixing creative tourism with other activities, are being developed through the practice itself. While guidance is offered through the IdeaLabs, further project mentoring and business planning support may be needed for some pilots. This work is challenged in two ways: On one hand, there is a lack of comprehensively researched, successful creative tourism business models internationally to reference; on the other hand, the scale of each activity is by nature limited, so the goal becomes a balancing act: to have enough visitors for economic sustainability but not too much to burden the community. 


\section{Concluding thoughts}

\section{Operational lessons learned}

Enabling capacity building processes for start-up activities and catalyzing networking dynamics for knowledge sharing and possible partnerships is foundational, especially for geographically dispersed initiatives located in small cities/towns and rural areas. Within this context, it is also essential to plan for the time necessary for start-up activities to be designed, planned, and implemented — a process lengthened with the participative involvement of local community organizations and actors. Network development also requires time for meeting, interacting, learning together, trustbuilding, and then collectively taking action(s).

Furthermore, although the small scale and flexibility of the creative tourism offers encourages learning-by-doing and processes of incremental improvement, and the IdeaLabs offer initial guidance and processes through which suggestions can be shared and ideas developed further, the establishment of an 'R\&D' phase for both product development and audience research—-before pilots are formally offering tourism products to the public_-may be advisable within similar projects.

Looking outward, significant attention to possible visitor-types and markets, and how to contact them, is imperative. The distinctiveness of each offer requires that this work is conducted at the level of each initiative and tailored to niche interest groups as well as tourism agents, supported more generally by central communications by the broader network/project. 


\section{The importance of place}

A growing multidisciplinary literature on the significance of place casts it as a 'meaningful location' (Lewicka, 2011), a “geographical space that is defined by meanings, sentiments and stories rather than by a set of co-ordinates" (Hague, 2005, p. 4). Brian Osborne (2006) calls attention to the "emotive power of imagined place" (p. 154), which highlights both the significance of landscapes in shaping identity as well as the important role of imagination and stories to "infuse the landscape with profoundly personal and localized meanings" (Opp and Walsh, 2010, p. 6). While research on place attachment is usually focused on residents (see Scannell and Gifford, 2010), we argue that a broader reception should be kept in mind.

Through locally developed creative tourism activities, this attachment to a placeboth affective and 'knowledge-enriched' — can be shared with visitors. This sharing process contributes to strengthening local identity and knowledge as well as to building a more ephemeral cognizance of dynamic means of meaning-making and, especially, the capacity of creative processes to probe and articulate aspects of place attachment and to spark memory-making among both visitors and residents. The development experiences in the start-up phase of CREATOUR reinforce these ideas, demonstrating that 'place'-in its expansive meaning-full elements and landscapesshould be an essential element throughout the creative tourism development process: as a source of inspiration and ideas, as a platform and immersive element in the design and implementation of a creative tourism offer, in the meaning-making interactions and creative expressions that are enabled, and in the memories that the visitors - and the hosts - take away from the creative activities. 


\section{Acknowledgements}

Thank you to Miroslav Tașcu-Stavre for background research on creative tourism, which contributed to this chapter.

This work was developed within the CREATOUR project (no. 16437), which is funded by the Portuguese Foundation for Science and Technology (FCT/MEC) through national funds and cofunded by FEDER through the Joint Activities Programme of COMPETE 2020 and the Regional Operational Programmes of Lisbon and Algarve.

\section{References}

Blapp, M. (2015). Creative Tourism in Bali's Rural Communities: Examination of the Current Offer and Advice on Future Product Development. MA thesis, NHTV University of Applied Sciences, Breda.

Bloom, J., S. Ritter, J. Kühnel, J. Reinders, \& S. Geurts. (2014). Vacation from work: A 'ticket to creativity'? The effects of recreational travel on cognitive flexibility and originality. Tourism Management, 44, 164-171.

Campos, A., Mendes, J., do Valle, P., \& Scott, N. (2015). Co-creation of tourist experiences: A literature review. Current Issues in Tourism, DOI: $10.1080 / 13683500.2015 .1081158$

Jelinčić, D., \& A. Žuvela. (2012). Facing the challenge? Creative tourism in Croatia. Journal of Tourism Consumption and Practice, 4(2).

Juanchich, L. (2007). Culture, tourisme et territoire : les apports du tourisme culturel au développement local. Lyon: Institut d'Etudes Politiques de Lyon. 
Leung, A. K. Y., W. W. Maddux, A. D. Galinsky, \& C.-Y. Chiu. (2008).

Multicultural experience enhances creativity: The when and how. American Psychologist, 63(3), 169-181.

Lewicka, M. (2011). Place attachment: How far have we come in the last 40 years? Journal of Environmental Psychology, 31(3), 207-230.

Maddux, W. W., H. Adam, \& A. D. Galinsky. (2010). When in Rome ... Learn why the Romans do what they do: How multicultural learning experiences facilitate creativity. Personality and Social Psychology Bulletin, 36(6), 731-741.

OECD. (2009). Impact of Culture on Tourism. Paris: OECD.

OECD. (2014). Tourism and the Creative Economy. Paris: OECD.

Opp, J., \& J. C. Walsh. (Eds.). (2010). Placing Memory and Remembering Place in Canada. Vancouver: UBC Press.

Osborne, B. (2006). From patriotic pines to diasporic geese: Emplacing culture, setting our sights, locating identity in a transnational Canada. Canadian Journal of Communications, 31(1), 147-175.

Pine, J. B. II, and J. H. Gilmore (1998). Welcome to the experience economy. Harvard Business Review, July-August, pp. 97-105.

Raymond, C. (2007). Creative tourism New Zealand: The practical challenges of developing creative tourism. In G. Richards \& J. Wilson (Eds.), Tourism, Creativity and Development (pp. 146-157). London: Routledge.

Richards, G. (2011). Creativity and tourism: The state of the art. Annals of Tourism Research, 38(4), 1225-1253.

Richards, G., \& C. Raymond. (2000). Creative tourism. ATLAS News, 23, pp. 16-20.

Richards, G., \& J. Wilson. (Eds.) (2007). Tourism, Creativity and Development. Abingdon: Routledge. 
Scannell, L., \& R. Gifford. (2010). Defining place attachment: A tripartite organizing framework. Journal of Environmental Psychology, 30, 1-10.

Triarchi, E., \& K. Karamanis. (2017). Alternative tourism development: A theoretical background. World Journal of Business and Management, 3(1).

UNESCO. (2006). Tourism, Culture and Sustainable Development. Paris: UNESCO.

UNWTO. (2016). Global Report on the Transformative Power of Tourism: A Paradigm Shift Towards a More Responsible Traveller. Madrid: UNWTO. 